\title{
Antioxidant Activity of Hexane, Chloroform, Acetone and Methanol Extract of Swietenia Macrophylla
}

\author{
Ushie, O. A. ${ }^{1 *}$, Neji, P.A. ${ }^{2}$, Abeng, F. E. ${ }^{2}$, Azuaga, T. I. ${ }^{1}$, Aikhoje, E.F. ${ }^{1}$, Adashu, J. M. ${ }^{1}$ \\ ${ }^{I}$ Department of Chemical Sciences, Federal University Wukari, Nigeria \\ ${ }^{2}$ Department of Chemistry, Cross River University of Technology Calabar, Nigeria
}

*Corresponding Author: Ushie, O. A., Department of Chemical Sciences, Federal University Wukari, Nigeria

\begin{abstract}
Antioxidant activities of methanol, acetone, chloroform and hexane extracts of Swietenia macrophylla leaves were evaluated. The antioxidant activity of the extracts. The antioxidant activity of $S$. macrophylla leaf extracts was evaluated using 1,1-diphenyl-2-picrylhydrazyl (DPPH.) radical scavenging assay in which all of the leaf extracts showed remarkable activities. At the concentration of $0.1 \mathrm{mg} / \mathrm{mL}$, the methanol extract, chloroform extract, acetone and the n-hexane extract showed $81.04 \%, 39.34 \%, 44.31 \%$ and $56.64 \%$ scavenging activities respectively.
\end{abstract}

Keywords: Antioxidant, DPPH, Extractions; Swietenia macrophylla

\section{INTRODUCTION}

Nature has always remained a great source of medicinal agents and medicinal system of the world has used plant-based medicines from time immemorial (Mudasir et al., 2011). Medicinal plants are the richest bio-resource of drugs of traditional systems of medicine, modern medicines, nutraceuticals, food supplements, folk medicines, pharmaceutical intermediates and chemical entities for synthetic drugs (Ncube et al., 2008). Oxidation is a chemical reaction that refers electrons from a substance to an oxidizing agent. Oxidation reaction can produce free radical which starts chain reactions that damage cells. Antioxidants terminate these chain reactions by removing free radical intermediates and inhibit other oxidation reation by oxidize themselves; as a result, antioxidants are often reducing agent such as thiols, ascorbic acid or pohyphenols (Sies, 1997, Kolapo 2014). Ushie et al., 2016 pointed out that $S$. macrophylla can be used as an analgesic, anaesthetic and as social drugs since it contains alkaloids. The alkaloids contained in plants are used in medicine as anaesthetic agents (Herourat et al.; 1988). Ushie et al., 2016 pointed out that S. macrophylla can be used in the treatment of certain illnesses because it contains glycosides which have long been employed as important ingredient for arrow poisons and drugs (Trease and Evans, 1989). The aim of this research project is to study the antioxidant properties of S. macrophylla using DPPH assay

\section{Materials AND Methods}

\subsection{Sample Collection, Preparation and Extraction}

The Swietenia macrophylla leaves were collected from their natural habitat in Bekwarra Local Government Area of Cross River State, Nigeria and were air dried for two weeks; the dried sample was chopped and grounded into fine powder. The extracts of the leaves were prepared by soaking 100 $\mathrm{g}$ of the sample in $250 \mathrm{ml}$ hexane for 72 hours with frequent agitation. The resulting mixture was filtered by gravity filtration and the filtrate was concentrated by evaporation using rotatory evaporator, kept in a vacuum oven over night at room temperature to remove all the solvent and weighed. The procedure was repeated on the residue using chloroform, acetone and methanol sequentially in order of polarity. The extracts were stored in a desiccator until required for testing. 


\subsection{Antioxidant Assay using DPPH Assay (2, 2-Diphenyl-1-Picrylhydrazyl)}

The radical scavenging activity of different extracts was determined by using DPPH assay according to Chang et al., (2001) and Rahman et al., (2016). The decrease in the absorption of the DPPH solution after the addition of an antioxidant was measured at $517 \mathrm{~nm}$. Ascorbic acid (10mg/ml DMSO) was used as reference.

\subsection{Principle}

2, 2- Diphenyl -1- Picryl Hydrazyl is a stable (in powder form) free radical with red color which turns yellow when scavenged. The DPPH assay uses this character to show free radical scavenging activity. The scavenging reaction between (DPPH) and an antioxidant (H-A) can be written as,

\section{$(\mathrm{DPPH})+(\mathrm{H}-\mathrm{A}) \quad \longrightarrow \quad \mathrm{DPPH}-\mathrm{H}+(\mathrm{A})$}

Antioxidants react with DPPH and reduce it to DPPH-H and as consequence the absorbance decreases. The degree of discoloration indicates the scavenging potential of the antioxidant compounds or extracts in terms of hydrogen donating ability.

\subsection{Reagent Preparation}

$0.1 \mathrm{mM}$ DPPH solution was prepared by dissolving $4 \mathrm{mg}$ of DPPH in $100 \mathrm{ml}$ of ethanol.

\subsection{Working Procedure}

Different volumes of the extract were taken and made up to $2 \mathrm{ml}$ with methanol. The following concentrations of the extract were tested $(0.1,0.3,0.5,0.7$, and $1.0 \mathrm{mg} / \mathrm{ml})$. Vitamin $\mathrm{C}$ was used as the antioxidant standard at concentrations $(0.1,0.3,0.5,0.7$, and 1.0 $\mathrm{mg} / \mathrm{ml}$ ). $0.5 \mathrm{ml}$ of $1 \mathrm{mM}$ of DPPH in ethanol was added to each of the sample solutions. A blank solution was prepared containing the same amount of methanol and DPPH. The sample solutions are incubated in the dark for 3ominutes before reading the absorbance at $517 \mathrm{~nm}$. The radical scavenging activity was calculated using the following formula:

Inhibition $(\%)=\underline{\mathrm{A}-\mathrm{B}} \times 100$

A

Where $\mathrm{A}=$ Absorption of the blank sample without extract.

$$
\mathrm{B}=\text { the absorption of the extract. }
$$

\section{RESULTS AND DISCUSSION}

To determined the antioxidant activity of a specific solution, there will be a significant decreased in the absorbance for sample which contain antioxidant compound (purple colour vanishing coupled with the yellow color build up clearly noticed by naked eye) the intensity of the yellow colour was directly proportional with the antioxidant activity in the tested solution, the higher scavenging indicate the higher activity (Sagare and Singh 2011). All the crude extracts of hexane, chloroform, acetone and methanol were subjected to DPPH radical scavenging assay using different concentrations. The data was presented in Table 1 and the form of line graphs (Figure 1-4).

Table1. Result of Antioxidant Activities Swietenia macrophylla hexane, chloroform, acetone and methanol extracts

\begin{tabular}{|c|c|c|c|c|c|}
\hline Extracts & & Concentrations & & & \\
\hline & 0.10 & 0.30 & 0.50 & 0.70 & 1.00 \\
\hline Chloroform & 0.00 & 9.72 & 16.11 & 33.65 & 39.34 \\
\hline Methanol & 35.67 & 51.66 & 57.82 & 71.09 & 81.04 \\
\hline Acetone & 0.00 & 25.36 & 32.27 & 41.94 & 44.31 \\
\hline Hexane & 22.27 & 36.97 & 37.2 & 52.37 & 56.64 \\
\hline
\end{tabular}

The crude hexane extract of Swietenia macrophylla displayed inhibition of DPPH radical scavenging activity at the range of $22.27 \%, 36.97 \%, 37.30 \%, 52.37 \%$ and $56.64 \%$ with the concentration of 0.1 , $0.3,0.5,0.7$ and $1 \mu \mathrm{g} / \mathrm{ml}$ respectively (Figure 1 ). 


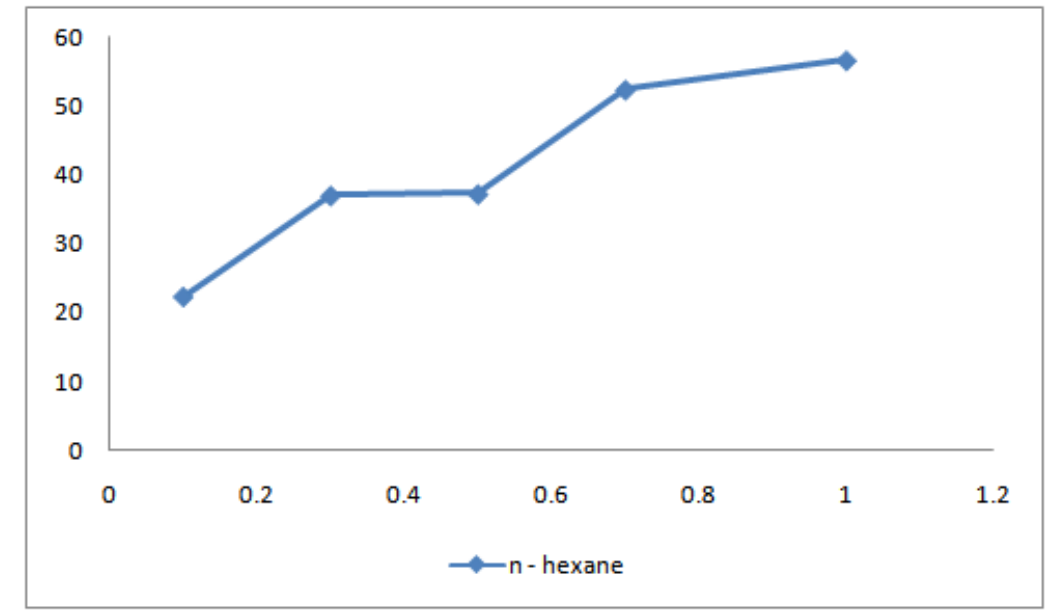

Figure1. Graph of Antioxidant Activities of Hexane

Figure 2 present the result of the crude chloroform extract of $S$. macrophylla which displayed inhibition of DPPH radical scavenging activity at the range of $0.00 \%, 9.72 \%, 16.11 \% 33.68 \%$ and $39.34 \%$ with the concentration of $0.1,0.3,0.5,0.7$ and $1 \mu \mathrm{g} / \mathrm{ml}$ respectively.

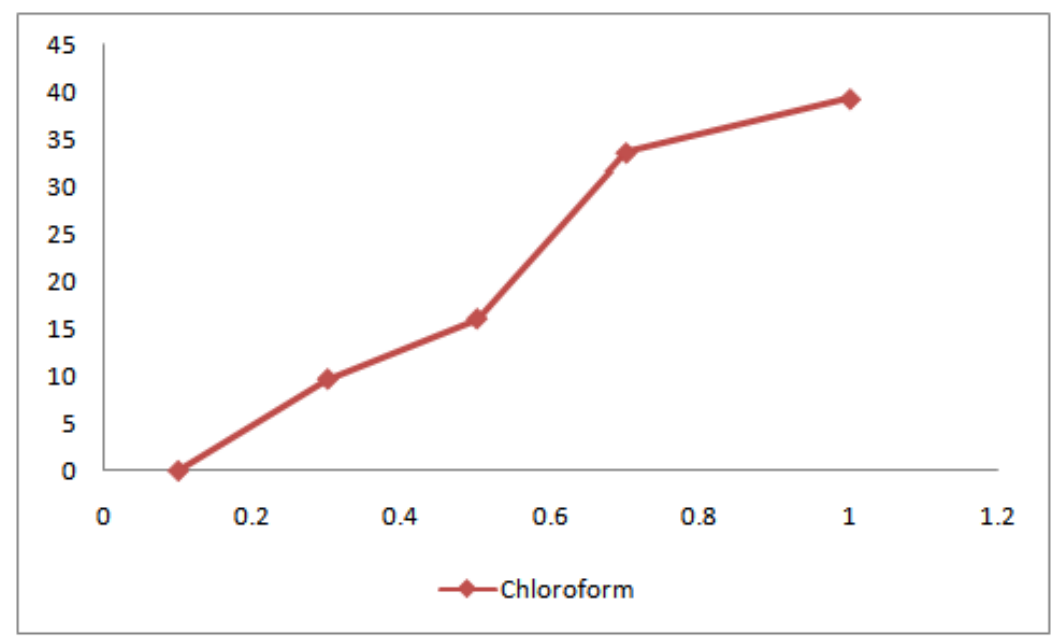

Figure2. Graph of Antioxidant activities of chloroform of Swietenia macrophylla

The crude acetone extract of $S$. macrophylla displayed inhibition of DPPH radical scavenging activity at the range of $0.00 \%, 9.72 \%, 16.11 \% 33.68 \%$ and $39.34 \%$ with the concentration of $0.1,0.3,0.5,0.7$ and $1 \mu \mathrm{g} / \mathrm{ml}$.

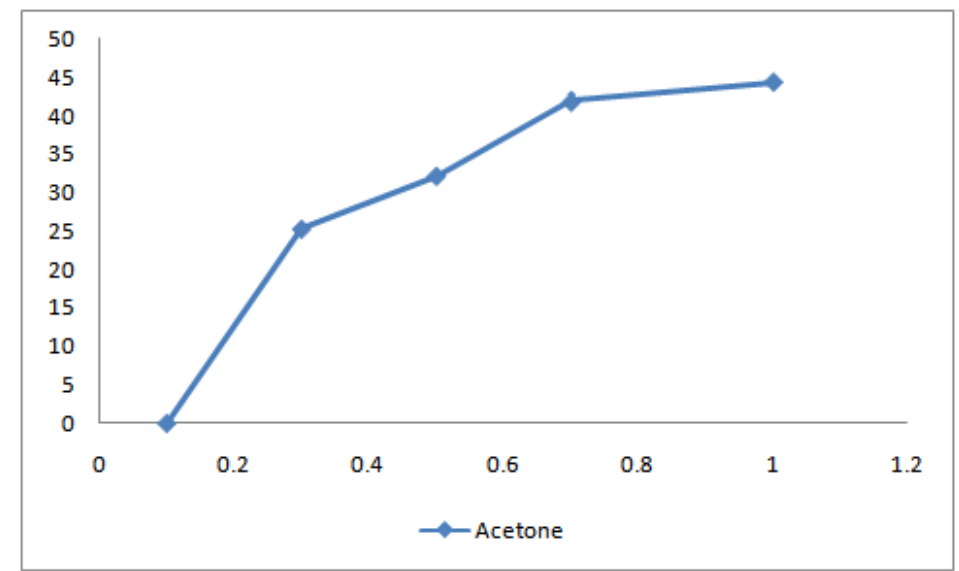

Figure3. Graph of Antioxidant Activities of Acetone of Swietenia macrophylla

The crude methanol extract of $S$. macrophylla displayed inhibition of DPPH radical scavenging activity at the range of $35.67 \%, 51.66 \%, 57.82 \% 71.09 \%$ and $81.04 \%$ with the concentration of 0.1 , $0.3,0.5,0.7$ and $1 \mu \mathrm{g} / \mathrm{ml}$. 


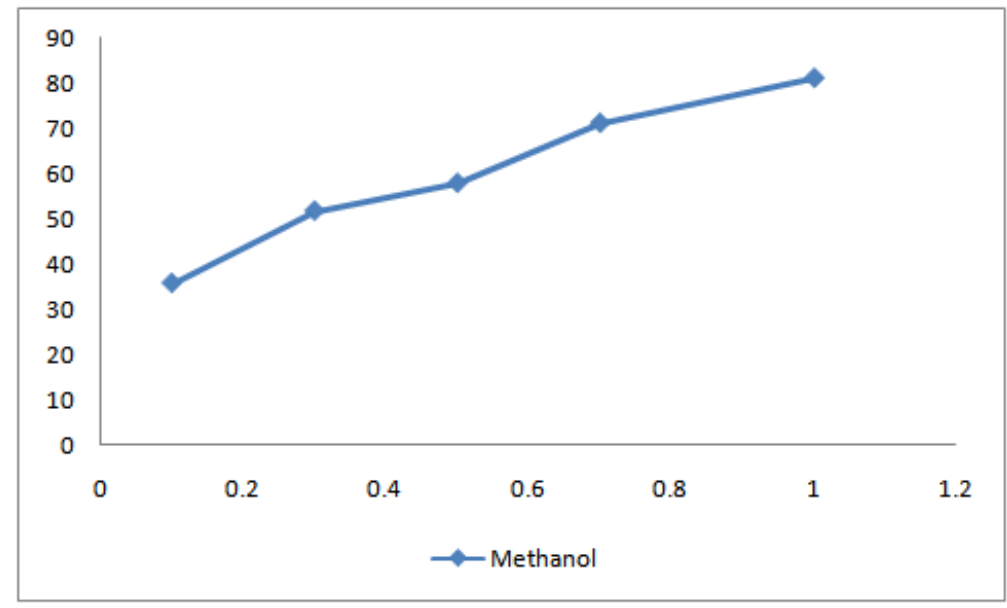

Figure4. Graph of Antioxidant Activities of Methanol of Swietenia macrophylla

Figure 5 is a graph and Figure 6 is the histograph showing the various percentage scavenging inhibition. It revealed that chloroform extract of $S$. macrophylla displayed the least inhibition of DPPH radical scavenging activity followed by by the acetone extract. Tne methanol extract of $S$. macrophylla displayed highest followed by the hexane extract. inhibition of DPPH radical scavenging activity

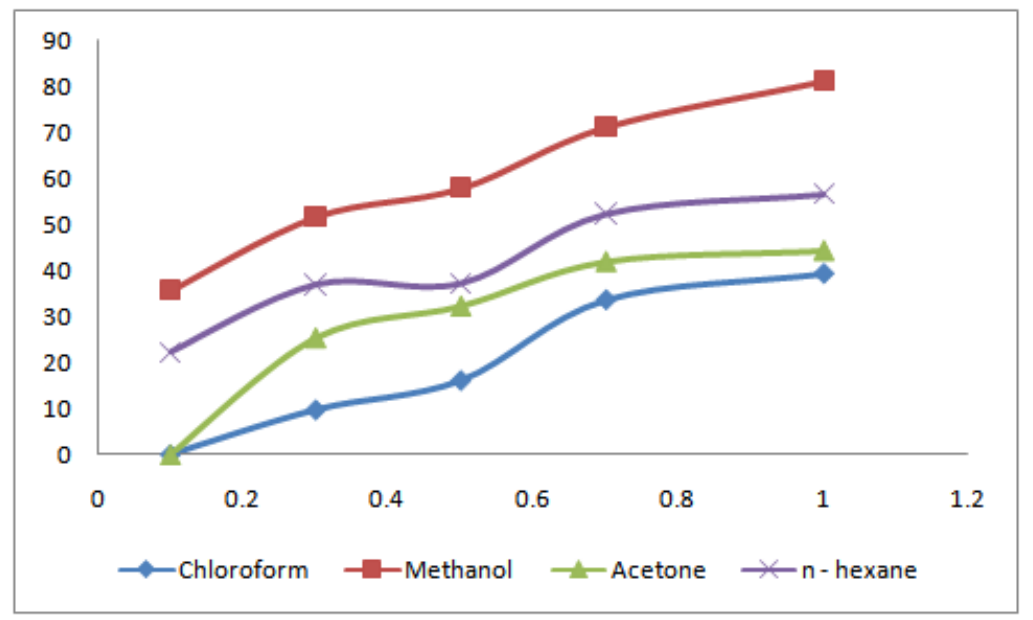

Figure5. Graph of Antioxidant Activities of hexane, chloroform, acetone and methanol of Swietenia macrophylla

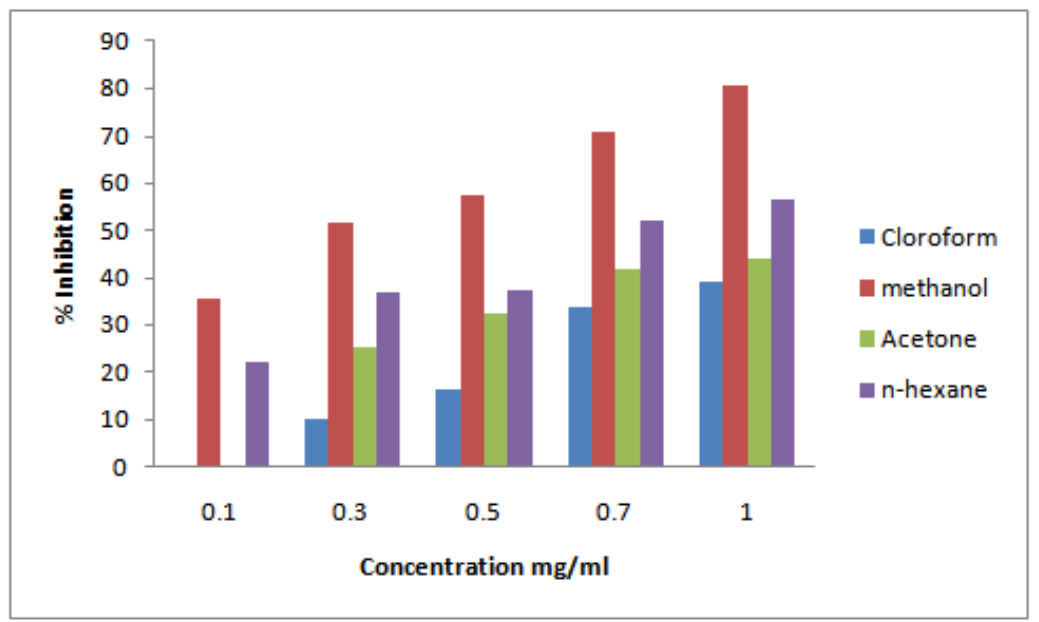

Figure6. Antioxidant activities of hexane, chloroform, acetone and methanol of Swietenia macrophylla

Kumar \& Sharma (2006) pointed out that the application of synthetic antioxidant possesses severe threats such as carcinogenicity, thus researchers have turned towards the use of herbal plants with efficient antioxidant property that is capable of defending the cells against the damaging effects of 
free radicals. Secondary metabolites are potent antioxidants, metal chelators or free radical scavengers which possess health promoting properties. As a rapid and simple measure of antioxidant activity, the DPPH radical scavenging capacity is based on the reduction of the stable radical DPPH to yellow coloured diphenylpicrylhydrazine in the presence of a hydrogen donor (Jothy et al., 2012).

\section{CONClusion}

The extracts (acetone, methanol, chloroform and hexane) of Swietenia macrophylla has been found to exhibit antioxidant properties and the leaf extract of the plant can be said to contain some compound that can be used to slow the oxidative reaction.

\section{REFERENCES}

[1] Chang, L. C., and A. D. Kinghorn (2001) Flavonoids as Cancer Chemopreventive Agents, In Tringali, Corrado (Ed.). Bioactive Compounds from Natural Sources. London:Taylor and Francis. 159-185

[2] Sagar B. Kedare and R. P. Singh (2011).Genesis and development of DPPH method of antioxidant assay. Food Sci Technol. 48(4): 412-422

[3] Herourat, D., Sangwin, R., S., Finiaux, M. A., Sangwan-Norrell , B.,S. (1988). Variations in the leaf alkaloid content of androgenic diploid plants of Daturu innoxia, Planta Medica, Journal of Medicinal Plant Research, 54: 14-20.

[4] Jothy, S. L., Azlan, A. A., Yeng, C. Y., \& Sasidharan, S. (2012). Antioxidant activity and hepatoprotective potential of Polyalthia longifolia and Cassia spectabilis leaves against paracetamolinduced liver injury. Evidence Based Complementary Alternative Medicine, 4, 714 - 730.

[5] Kolapo, A. L., Okunade, M. B., Adejumobi, J. A. and Ogundiya, M. O. (2009). Phytochemical Composition and Antimicrobial Activity of Prosopis. Africana. 5 (1): 90 - 93.

[6] Kumar, V., \& Sharma, S. K. (2006). Antioxidant studies on some plants: A review. Hamdard Medicus (Pakistan), 4, 25-36

[7] Mudasir, A.; Mir, R.T.S.; Rameashkannan, M. V.; Riyaz, A.; Pala, M.; B 2011. A comparative study of phytochemical analysis amd antimicrobial properties of stigmas and stamens of saffron (Crocus sativus L.) found in Kashmir. Adv Bio Tech., 11(6):35-38

[8] Ncube NS, Afolayan AJ, Okoh AI. 2008 Assessment techniques of antimicrobial properties of natural compounds of plant origin: current methods and future trends. African Journal of Biotechnology; 7 (12): 1797-1806

[9] Rahman, T. U., Khan, T., Khattak, K. F., Ali. A., Liaqat, W., et al. (2016). Antioxidant Activity of Selected Medicinal Plants of Pakistan. Biochem Physiol 5:208. doi:10.4172/2168-9652.1000208

[10] Sies, H. (1997) Oxidative stress: oxidant and antioxidant. Exp. Physio. 82(2):291-295

[11] Trease G. E and Evans W. C, 1989). Pharmacolognosy, baillere tindall, London pp. 45-50

[12] Ushie O. A., Onen, A. I., Ugbogu, O. C., Neji, P. A. \& Olumide,V. B. (2016) Phytochemical Screening and Antimicrobial Activities of Leaf Extracts of Swietenia macrophylla, ChemSearch Journal 7(2): 6469.

[13] Ushie, O. A., Egwaikhide, P. A. \& Longbab, B. D. (2016). Phytochemical Screening of Some Medicinal Plants in Local Areas of Taraba State, Nigeria. International Journal of Applied Research and Technology. 5(9): 27-32.

Citation: Ushie, O. A., et.al, "Antioxidant Activity of Hexane, Chloroform, Acetone and Methanol Extract of Swietenia Macrophylla”. International Journal of Clinical Chemistry and Laboratory Medicine (IJCCLM), 5(4), pp.6-10, DOI: http://dx.doi.org/ 10.20431/2455-7153.0504002.

Copyright:(C) 2019 Authors. This is an open-access article distributed under the terms of the Creative Commons Attribution License, which permits unrestricted use, distribution, and reproduction in any medium, provided the original author and source are credited. 